Operation in the Country," Miss Crawford; "Long case Nursing," Dr. Horner; "The Nursing of Diphtheria," Miss Mathieson; "The Nurse from a Patient's Point of View," Mrs. John Maynard Harlan; "In Case of Death," Miss Boeckmann; "Some Problems of the Nurse in a Small Town," Miss Barns.

Of the papers promised are: "Cancer," Miss Baxter; "Care of an Incubator Baby," Miss Christie; subject unknown, Miss Holmes; "Care of the Aged," Miss Breeze; "Common Things in Nursing," Miss Eldridge; "The Nurse as a Home Missionary," Miss Wilson; "The Record Sheet," Miss Farr; "Consideration due the Helpless," Miss Beatle; "Eclampsia," Miss Campbell; "Chorea," Miss Patterson; "Milk Modification," Sister Amy; "Cleanliness versus Asepsis," Miss Schumacher, and papers on subjects not chosen, by Miss Rommell, Miss Bettys and Miss Dorsey.

It is our ambition to be able to give more space to the discussion of hospital and training-school administration, and methods of instruction in training-schools. These subjects, we think, are peculiarly vital at this time. It has always been our ambition to open a department for the home, and to give a condensed report each month of the broader lines of work in which women are engaged, that correlate either directly or indirectly with nursing; but before we can so broaden the pages of the magazine the business side must be looked to. A little more vigorous coöperation from all the forces interested would carry the Journal forward upon these lines, and make the coming year still greater than the last.

\title{
SOME INFORMATION ASKED FOR
}

ONE of our correspondents in a small western city, has asked us to ascertain, through the pages of the Journal, what success nurses have had or are having in the establishment and management of private hospitals. We have been able to furnish her personally very little information, as our acquaintance with nurses who have experimented along these lines has been somewhat limited, but we know there are nurses who have succeeded and others who have failed, and we would like very much to hear from both classes as to the result of their experiments. Of course this correspondent must look, first, to the financial side of the enterprise, the cost of equipment, rent, service, etc., and she also will wish to know how quickly the public responds and what support the medical profession may be depended upon to give, when a hospital of this kind is first started.

From a still farther northern section, comes a request for papers 
on the management of hospitals, to embody the work of a nursing superintendent, her power and authority, her relation to the medical staff, the appointment of substitutes, vacations, etc.

We have also heard from a subscriber in a far eastern section of the country, telling us of the great value that Miss Noyes' paper on the small hospital laundry has been to her. It so happened that at the time the article was published, in our July issue, the question of the equipment of a laundry was having to be settled in the hospital of which she is the superintendent. This writer begs for more papers of a practical kind on all the subjects pertaining to the equipment and administration of small hospitals. We feel very sure that many of our readers are having special experiences that would be of great value to others engaged in the same line of work in hospitals, and we hope that during the coming yeat they may be moved to give more of their knowledge to their fellow workers.

\section{TIME TO RENEW}

We would remind our subscribers that there are a great many expirations with the September number. Do not risk breaking your file by delaying. Renew now. 